\title{
Effect of the Head-Group Geometry of Amino Acid-Based Cationic Surfactants on Interaction with Plasmid DNA
}

\author{
Vaibhav Jadhav and Souvik Maiti* \\ Institute for Genomics and Integrative Biology, CSIR, Mall Road, Delhi 110 007, India \\ Antara Dasgupta and Prasanta Kumar Das* \\ Department of Biological Chemistry, Indian Association for the Cultivation of Science, Jadavpur, \\ Kolkata - 700032, India \\ Rita S. Dias, ${ }^{*,+\neq}$ Maria G. Miguel, ${ }^{\ddagger}$ and Björn Lindman ${ }^{\dagger, \neq}$ \\ Physical Chemistry 1, Centre for Chemistry and Chemical Engineering, University of Lund, S-221 00 Lund, \\ Sweden, and Departamento de Química, Universidade de Coimbra, 3004-535 Coimbra, Portugal
}

Received January 24, 2008; Revised Manuscript Received April 8, 2008

\begin{abstract}
The interaction between DNA and different types of amino acid-based cationic surfactants was investigated. Particular attention was directed to determine the extent of influence of surfactant head-group geometry toward tuning the interaction behavior of these surfactants with DNA. An overview is obtained by gel retardation assay, isothermal titration calorimetry, fluorescence spectroscopy, and circular dichroism at different mole ratios of surfactant/DNA; also, cell viability was assessed. The studies show that the surfactants with more complex/ bulkier hydrophobic head group interact more strongly with DNA but exclude ethidium bromide less efficiently; thus, the accessibility of DNA to small molecules is preserved to a certain extent. The presence of more hydrophobic groups surrounding the positive amino charge also gave rise to a significantly lower cytotoxicity. The surfactant self-assembly pattern is quite different without and with DNA, illustrating the roles of electrostatic and steric effects in determining the effective shape of a surfactant molecule.
\end{abstract}

\section{Introduction}

A physicochemical study of the interaction between DNA and cationic lipid molecules and other cationic agents ${ }^{1}$ such as peptides, linear polyamines, ${ }^{2}$ dendrimers,${ }^{3}$ and nanoparticles will facilitate the understanding of the cellular function such as DNA packaging, transfection in mammalian cells, control of transcription, and, most importantly, efficient gene delivery. There has been an immense interest among biologists and chemists in characterizing the nature of the fundamental interactions between cationic agents and DNA; furthermore, several general approaches have been designed to study such interactions. One of the important driving forces, which play a major role in the formation of these complexes is the electrostatic interaction, but the role of hydrophobic interactions cannot be ruled out. Most extensive studies in this regard have focused on the interaction between DNA and conventional cationic surfactants that are commercially available, like long chain alkyl groups with trimethylammonium ion as the head group. ${ }^{4-11}$

The interactions of nucleic acids with peptides have received a great interest from researchers in the last couple of years, one of the underlying purposes being of using naturally occurring or synthetic peptides as gene delivery systems. ${ }^{12-17}$ The approach of using proteins for DNA delivery is based upon the observation that the functionally active regions of proteins such

* To whom correspondence should be addressed. Fax: +91 1127667471 (S.M.); +91 3324732805 (P.K.D.); +351 239854466 (R.S.D.). E-mail: souvik@igib.res.in (S.M); bcpkd@iacs.res.in (P.K.D); rsdias@qui.uc.pt (R.S.D.).

University of Lund.

Universidade de Coimbra. as enzymes, receptors, and antibodies are relatively small, typically consisting of around $10-20$ amino acids. A number of peptide sequences have been shown to be able to bind to and condense DNA and rational design of peptide sequence has also been used to develop completely synthetic DNA-binding peptides. ${ }^{12-21}$ Recent studies suggest that the amino acid composition of the copolymers has an impact on protection of DNA against degradation by the nucleases, as well as on cytotoxicity and transfection efficiency. ${ }^{17,22}$

Amphiphilic molecules are very popular in nanotechnology due to their self-assembly properties. Because compaction of DNA occurs when cationic surfactant aggregates are formed in its vicinity, this allows for a good control of the compaction/ decompaction of DNA just by changing the properties of the solution or using other elegant approaches such as the control induced by light. ${ }^{23}$ The self-assembly properties are thus very promising, and the concept has been tested with other positively charged agents to improve their efficiency and control. This was demonstrated with, for example, hydrophobically modified spermidine $^{24,25}$ and amphiphilic peptides (lipopeptides). ${ }^{15,26,27}$

The self-assembly of amphiphilic molecules, like surfactants, can lead to a large variety of structures, including discrete spherical or slightly anisometric aggregates, long cylindrical aggregates, and bilayers. The type of self-assembly structure formed depends on the optimal packing of the amphiphilic molecules, which in turn can be related to the balance between hydrophilic and hydrophobic properties. A simple model based on the effective shape of a surfactant molecule, notably the relative cross-sectional areas of the hydrophilic and hydrophobic 
parts can successfully capture the main features of surfactant self-assembly. ${ }^{28-30}$

In the present study, we introduce some novel amino acidbased cationic surfactants, having bulky polar heads as well as hydrophobic groups. Ionic surfactants typically associate into globular or cylindrical micelles characterized by a larger crosssection of the polar than the nonpolar part. The large effective area of the hydrophilic group is for classical surfactants determined by electrostatic effects, given by an effective repulsion between the head groups. Therefore, if the electrostatic head-group interactions are screened, for example, by adding electrolyte, the effective head-group size decreases, and a transition to other types of self-assemblies occurs. For the surfactants introduced here, the behavior will be different because the reduction in effective head-group size is counteracted by the bulky head groups. A further feature that is introduced relative to classical surfactants is the presence of a pronounced hydrophobicity, leading to an attraction force between head groups.

In the presence of an oppositely charged polyelectrolyte, the self-assembly of an ionic surfactant is dramatically facilitated. Thus, the onset of self-assembly, as defined for example by the critical micelle concentration (CMC), occurs at concentrations that are lower by orders of magnitude ${ }^{31}$ and the phase diagrams are strongly modified. ${ }^{32,33}$ This can be attributed mainly to a more or less complete elimination of the electrostatic repulsions between head groups and, thus, to a major decrease of the effective head-group size. A large number of studies of the interaction between DNA and simple cationic surfactants have illustrated this expected behavior. In the present study, where we consider more complex cationic surfactants, we consider a more intricate association pattern. First, the surfactants studied have bulky head groups that counteract largely a major decrease in effective headgroup size on association with DNA. Second, the head groups have hydrophobic features leading, as mentioned, to an attraction between head groups. However, this is not the only effect of head-group hydrophobicity. We also have to consider the hydrophobic interaction between the head groups and the bases of DNA, introducing another feature in the DNA - surfactant association. We have recently argued that the hydrophobic interactions have been somewhat neglected in the behavior of DNA; ${ }^{34}$ while the hydrophobic interactions between bases drive the DNA self-assembly into the double helix they are also important in association with surfaces, ${ }^{35}$ surfactants, ${ }^{4}$ as well as with polymers. ${ }^{36}$

Following this reasoning, to further understand the role of the head group of the amphiphilic molecules on the DNAsurfactant interactions, which we hope will contribute to the optimization of cationic lipid formulations for efficient gene delivery in therapeutics and fundamental cell biological studies, we sought to synthesize three surfactants with amino acids as the surfactant head (surfactants Ala, Pro, and Phe, Scheme 1).

In the present paper we study surfactants with head groups presenting different hydrophobicities. The interaction behavior of the surfactants with DNA was investigated by gel retardation assay, fluorescence spectroscopy, isothermal titration calorimetry, and circular dichroism at different mole ratios of surfactant/ DNA; also, cell viability was determined by an MTT assay.

\section{Materials and Methods}

Materials. pUC19 plasmid DNA (2.6 kbp) was used throughout. The plasmid was isolated from DH5- $\alpha$ cells by alkali lyses method and purified using the standard procedure of phenol chloroform
Scheme 1
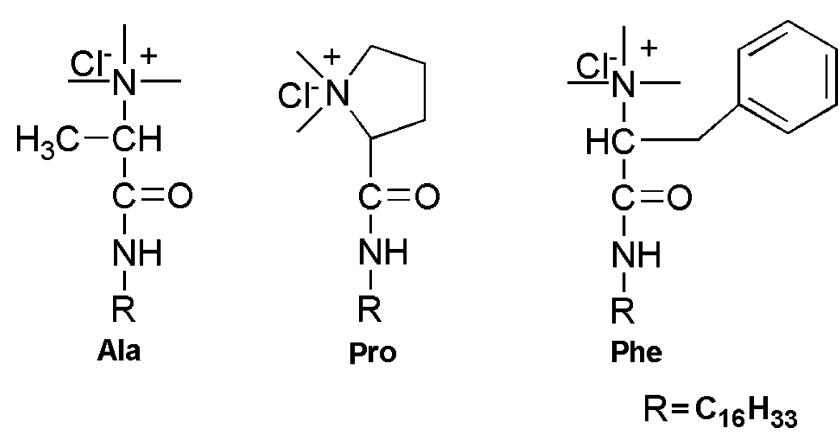

extraction. Its purity (98\%) was confirmed on $1 \%$ agarose gel and by UV spectrophotometer taking the OD at 260 and $280 \mathrm{~nm}$. All reagents for the surfactant synthesis were highest purity and used as received. Ethidium bromide (EB) (Aldrich) was used as received. Unless specified, all solutions and experiments were prepared and conducted using $10 \mathrm{mM}$ sodium phosphate buffer $(\mathrm{pH}$ 7.0) prepared with Milli-Q water.

Synthesis of Surfactants (Scheme 1). The detailed synthetic procedure for the surfactants Ala, Pro, and Phe is available in a previous report. ${ }^{37}$ Briefly, Boc-protected L-amino acids $(10 \mathrm{mmol})$ were coupled with $n$-hexadecylamine (11 mmol) using $N, N$-dicyclohexylcarbodiimide (DCC, $11 \mathrm{mmol}$ ) as the coupling reagent in the presence of 4-N,N(dimethylamino)pyridine (DMAP, $11 \mathrm{mmol}$ ). Deprotections of Bocgroups were carried out using trifluoroacetic acid (TFA, 4 equiv) in dry DCM. After $2 \mathrm{~h}$ of stirring, solvents were removed on a rotary evaporator, and the mixture was taken into ethyl acetate. The ethyl acetate part was thoroughly washed with aqueous $10 \%$ sodium carbonate solution followed by brine washing to neutrality. The organic parts were dried over anhydrous sodium sulfate and concentrated to get the corresponding amines. The produced amines ( 1 equiv) were quaternized with excess iodomethane using anhydrous potassium carbonate (2.2, 1.1, and 2.2 equiv for Ala, Pro, and Phe, respectively) and a catalytic amount of 18-crown-6-ether in dry DMF for $2 \mathrm{~h}$. The reaction mixtures were taken into ethyl acetate and washed with aqueous sodium thiosulfate and brine solution. The concentrated ethyl acetate parts were crystallized from methanol/ether to obtain solid quaternized iodides, which were then subjected to ion exchange on an Amberlyst A-26 chloride ion-exchange resin column to get the pure desired surfactant. Overall yields were in the range of $70-80 \%$.

Gel Retardation Assay. The electrophoretic mobility of the cationic surfactant/DNA complexes was determined by gel electrophoresis using $1.0 \%$ agarose gel in a buffer consisting of $45 \mathrm{mM}$ Tris-borate and 1 mM EDTA at pH 8.0. Experiments were run at $80 \mathrm{~V}$ for $90 \mathrm{~min}$. About $1 \mu \mathrm{g}$ in $25 \mu \mathrm{L}$ (equivalent to $152 \mu \mathrm{M}$ in terms of negative charge $)^{38}$ of DNA was mixed with different amounts of surfactant solutions to achieve the desired charge ratio and incubated for $1 \mathrm{~h}$ prior to running the gel. DNA was visualized under UV illumination by staining the gels with ethidium bromide at room temperature.

Isothermal Titration Calorimetry. Isothermal titration calorimetry was performed with a VP-ITC Microcal (Northampton, MA) at $25^{\circ} \mathrm{C}$. The cell volume was $1.3438 \mathrm{~mL}$. After careful washing, the cell was prerinsed with the portion of the same DNA solution before each titration experiment. The concentration of the DNA phosphate groups (nucleotides) in the cell was $100 \mu \mathrm{M}$ at the beginning of the titration. Series of surfactant solutions of $2 \mathrm{mM}$ were injected in 30 portions of $10 \mu \mathrm{L}$ with a $250 \mu \mathrm{L}$ injection syringe, at 5 min intervals. A control experiment was carried out for each surfactant to find out the heats of surfactant dilution by omitting DNA from the solution in the cell. To obtain the heat of binding, the heat of dilution was subtracted from heat of observation $\left(\Delta H_{\mathrm{obs}}\right)$.

Ethidium Bromide Exclusion Assay. Ethidium bromide (EB) at 5 $\mu \mathrm{M}$ and $10 \mu \mathrm{M}$ DNA solution (one ethidium bromide per base pair) were mixed and allowed to incubate at $25{ }^{\circ} \mathrm{C}$ for $10 \mathrm{~min}$. Various amounts of surfactant solutions were added to the DNA-EB mixture 
and left to incubate for $30 \mathrm{~min}$. Fluorescence intensity was measured using a spectrofluorometer (FluoroMax-3, Spex) after diluting to $2 \mathrm{~mL}$ with the phosphate buffer. The excitation $\left(\lambda_{\mathrm{ex}}\right)$ and emission $\left(\lambda_{\mathrm{em}}\right)$ wavelengths were 480 and $600 \mathrm{~nm}$, respectively.

Circular Dichroism. Circular dichroism was performed using a J-715 spectropolarimeter (Jasco, Easton, MD). Spectra were acquired in a $1 \mathrm{~mm}$ path length quartz cuvette for various amounts surfactant to DNA mixing ratios $\left(Z_{+/-}\right)$for all surfactants at $25^{\circ} \mathrm{C}$; the temperature was maintained with a Peltier device. Spectra were measured as the average of three scans from 200 to $350 \mathrm{~nm}$ at a scan rate of $20 \mathrm{~nm} /$ min and with the buffer signal subtracted. Data analysis was performed with Excel 2000 (Microsoft, Redmond, WA) and Origin 6.0 (Microcal Software, North Hampton, MA) was used for smoothing and plotting.

Cytotoxicity Measurements (MTT Assay). HeLa cell line was obtained from NCCS, Pune, India and grown in MEM media [GibcoBRL, New York] supplemented with $10 \%$ fetal calf serum [Biological Industries, Israel], $2 \mathrm{mM}$ L-glutamine [Sigma], $1 \mathrm{mM}$ sodium pyruvate [Sigma], and antibiotic-antimycotic solution (100×; Sigma] at $37{ }^{\circ} \mathrm{C}$ in a humidified incubator with $5 \% \mathrm{CO}_{2}$. Cells were detached from the culture flask using trypsin-EDTA [Sigma] when they became 70-80\% confluent. The HeLa cells were seeded on a 96-well plate at a density of approximately $25 \times 10^{3}$ cells/well. After $24 \mathrm{~h}$ of incubation, the cationic surfactant $(0.1-25 \mu \mathrm{M})$ was added to the appropriate wells and incubated for $24 \mathrm{~h}$. Subsequently, methyl thiazol tetrazolium (MTT) assay was performed. A total of $10 \mu \mathrm{L}$ of $5 \mathrm{mg} / \mathrm{mL}$ MTT solution (MTT dissolved in Hank's balanced salt solution (HBSS); Sigma) was added to each well and incubated for $4 \mathrm{~h}$. Accumulated formazan crystals were solubilized in $200 \mu \mathrm{L}$ of DMSO [Sigma] and placed on a shaker for $15 \mathrm{~min}$. The absorbance at 560 and $630 \mathrm{~nm}$ was recorded in an ELISA plate reader (Spectra MAX 190, Molecular Devices).

\section{Results and Discussion}

The influence of the surfactant head-group chemistry toward tuning the interaction behavior of these cationic surfactants, containing amino acid head groups, with DNA was determined by gel retardation assay, isothermal titration calorimetry (ITC), fluorescence spectroscopy (FS), and circular dichroism (CD) at different mole ratios of surfactant/DNA. Cell viability was also determined by the MTT assay.

As a background to our discussion, some remarks about the interaction between polyelectrolytes and oppositely charged surfactants are useful. For a highly charged polyion like DNA, there is a very significant accumulation of the small counterions (sodium) in the vicinity of the polyion. The counterion distribution can for monovalent ions be understood from simple electrostatic considerations (Poisson-Boltzmann theory); terms like counterion "binding" or "condensation" are used to describe the enhanced counterion concentration close to the polyion, the latter being preferred as there is no stoichiometric association or association to individual sites but to the polyion as a whole. As an ionic surfactant is added, the surfactant ions will constitute part of the "condensed" counterions. When the local surfactant concentration reaches the critical micelle concentration (CMC), the surfactants will micellize; this occurs at a bulk concentration, which is the critical association concentration (CAC). ${ }^{31}$ For DNA interacting with cationic surfactants, there are several determinations of the CAC, found to be orders of magnitude below the CMC. ${ }^{5,9,10,39,40}$ The surfactant aggregates will act as counterions of very high valency and will, therefore, interact strongly with DNA and have a significant influence on, for example, its conformation. We recall that the reason why surfactants are efficient condensing agents is that they selfassemble into micellar aggregates in the vicinity of the DNA molecules. The vast majority of the studies on DNA condensation by cationic surfactants were performed with monovalent

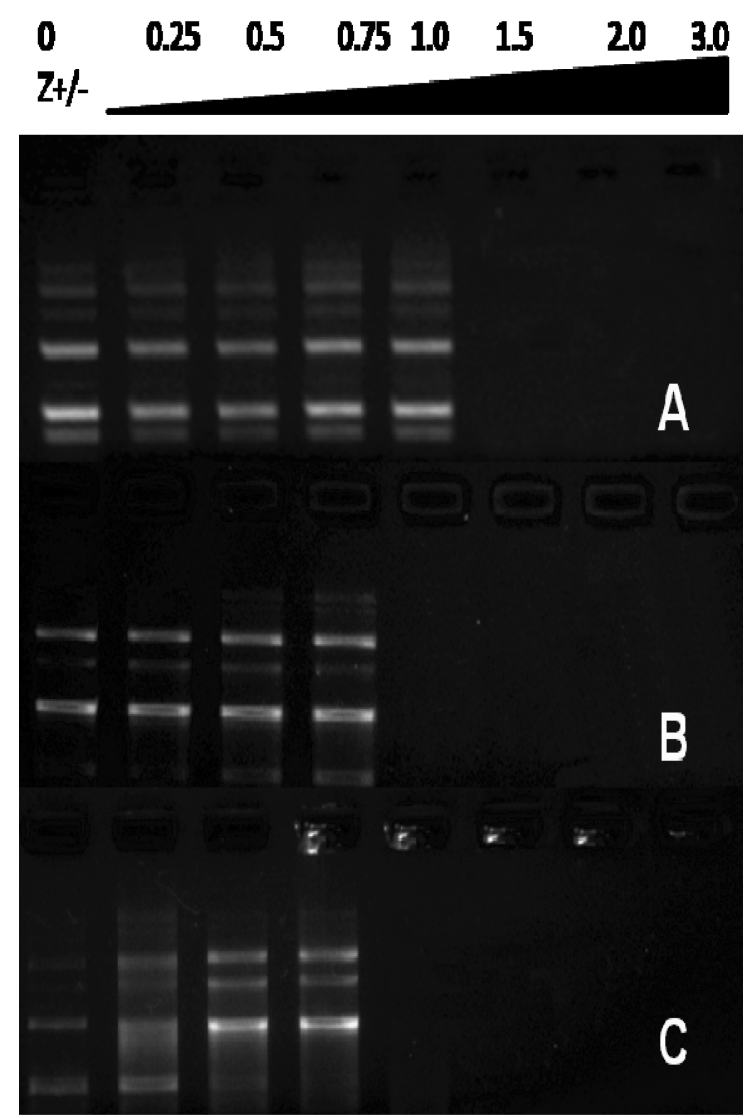

Figure 1. Gel retardation assay for (A) Ala, (B) Pro, and (C) Phe. The DNA concentration was $40 \mu \mathrm{g} / \mathrm{mL}$ ( $152 \mu \mathrm{M}$ in phosphate groups) and the surfactant to DNA mixing ratio, $Z_{+/-}$, is indicated in the figure. TBE buffer was used in these experiments.

surfactants. Monovalent species are not able to condense DNA, especially at such low concentrations (a few $\mathrm{mM}$ ). In fact, fluorescent molecules have been used to probe the environment of the DNA-surfactant complexes and to show that there are hydrophobic regions within the complex with an environment similar to that of micelles. ${ }^{41}$ Also, as we and others have shown, the surfactant aggregates in the vicinity of DNA can have different structures, including spheres, ${ }^{42}$ rods (hexagonal phase), ${ }^{35,39,43-48}$ and bilayers (lamellar phase), ${ }^{2,49-51}$ depending on the properties of the surfactant and the strength of the DNA-surfactant interaction. We can also note that the ionization of a surfactant can change on association to an oppositely charged polyion. Thus, the ionic form of a cationic surfactant will be favored close to DNA; in our case, this stabilization (shift of $\mathrm{p} K_{\mathrm{a}}$ ) will ensure that the surfactants studied here will always be in the cationic form.

Agarose Gel Electrophoresis. Images of the agarose gels of a series of surfactant/DNA complexes of different charge ratios are shown in Figure 1. At low charge ratios of surfactant to DNA an excess of uncomplexed DNA was present as shown by the migration of the DNA bands. The migration of the plasmid DNA in the gel was retarded as the ratio of surfactant to DNA was increased above the charge neutralization for all three surfactants, indicating that the surfactants were capable of bind to DNA, neutralizing its charges. However, there are clear differences between the gels of the three surfactants; the retardation of the DNA occurred for mixing ratios, $Z_{+/-}$, of 1.0, 0.75, and 0.75, for Ala, Pro, and Phe, respectively.

Considering the CMC of the three surfactants, shown in Table 1 , it is observed that Ala, the surfactant with the highest value of CMC of the three, induces a retardation of DNA for higher 
Table 1. Critical Micellar Concentration (CMC) for the Surfactants Ala, Pro, and Phe ${ }^{a}$

\begin{tabular}{ccc}
\hline surfactant & $\begin{array}{c}10^{4} \times \mathrm{CMC}, \\
(\mathrm{M} \text {; tensiometry })\end{array}$ & $\begin{array}{c}10^{4} \times \mathrm{CMC}, \\
(\mathrm{M} ; \text { fluorescence })\end{array}$ \\
\hline Ala & 4.29 & 4.85 \\
Pro & 1.76 & 1.95 \\
Phe & 2.12 & 2.46 \\
\hline
\end{tabular}

${ }^{a}$ As measured by surface tension and fluorometry. The values were taken from ref 37 .

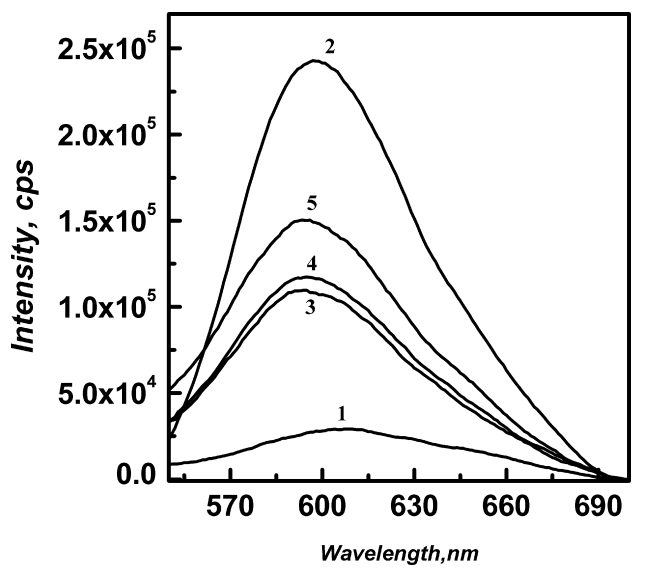

Figure 2. Fluorescence emission spectra of ethidium bromide (EB) (Trace 1), EB-plasmid DNA complex (Trace 2), and EB-plasmid DNA complexes in the presence of saturating amounts of Ala, 10 $\mu \mathrm{M}$, (Trace 3), Pro, $8 \mu \mathrm{M}$ (Trace 4), and Phe, $6 \mu \mathrm{M}$ (Trace 5), respectively. The concentration of plasmid DNA was $10 \mu \mathrm{M}$ in phosphate groups in $10 \mathrm{mM}$ sodium phosphate buffer $(\mathrm{pH} 7.0)$.

ratios than those with more complex head groups, such as proline and phenylalanine. These last two present very similar values of the CMC. It has been observed previously that surfactants with more hydrophobic head groups present lower CMC values, and accordingly, the CAC also decreases ${ }^{52}$ in the same fashion as increasing the alkyl chain length. ${ }^{9,53}$

These observations follow the arguments given above that ionic surfactants have high CMC values due to electrostatics, but that the electrostatic head-group repulsion is counteracted, when there is a hydrophobic attraction between head groups. DNA effectively screens the electrostatic head-group repulsion and strongly facilitates surfactant self-assembly. It is significant that the more hydrophobic surfactants associate to DNA at lower concentrations, indicating an important role of hydrophobic surfactant-DNA interactions.

Ethidium Bromide Exclusion Assay. The binding of surfactants to plasmid DNA was also investigated by the titration of surfactants with a premixed solution of DNA and ethidium bromide (EB). EB is a cationic dye that is widely used as a probe for native DNA. The ethidium ion displays a dramatic increase in fluorescence efficiency when it intercalates into DNA. The displacement of EB from DNA upon complex formation with cationic lipids and polycations has been used extensively in the development of nonviral gene delivery systems. The addition of cationic agents to premixed DNA-EB solutions results in the displacement of intercalated EB from the DNA/EB complexes resulting in the quenching of the fluorescence intensity. Figure 2 shows the fluorescence emission spectra of free EB (Trace 1), DNA/ EB complex (Trace 2), and DNA/EB complexes in the presence of sufficient surfactant to achieve saturation in the fluorescence quenching, for Ala (Trace 3), Pro (Trace 4), and Phe (Trace 5). The fluorescence quenching was observed in all cases; however, the extent of the quenching varies

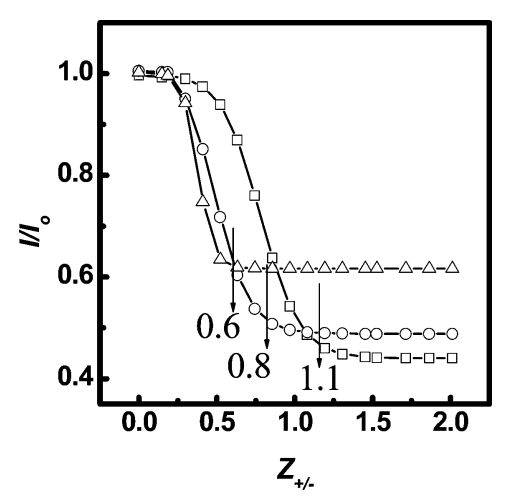

Figure 3. Ethidium bromide exclusion results for Ala $(\square)$, Pro $(\bigcirc)$, and Phe $(\Delta)$ plotted as $I / I_{0}$ versus the mixing ratio of cationic surfactant to DNA phosphate groups, $Z_{+/-}$. Plasmid DNA concentration was 10 $\mu \mathrm{M}$ in phosphate groups in $10 \mathrm{mM}$ sodium phosphate buffer $(\mathrm{pH} 7.0)$. The arrows indicate the saturation of the fluorescence quenching for this particular experiment.

notably from surfactant to surfactant. As shown in Figure 2, Ala is the most efficient to quench the fluorescence followed by Pro and Phe. In addition, typical curves of fluorimetric titrations of solutions of the DNA-EB complex with the different surfactants are shown in Figure 3. As can be seen, the saturation concentration of the fluorescence quenching also varies significantly among the surfactants. Saturation occurs at a $Z_{+/-}$value of $1 \pm 0.1$ in the case of Ala, whereas it occurs at $Z_{+/-}$values of $0.75 \pm 0.1$ and $0.6 \pm 0.1$ in the case of Pro and Phe, respectively. This sequence of interaction is in good agreement with the results obtained in the gel electrophoresis experiments (Figure 1).

The fact that Ala quenches the EB fluorescence more efficiently but at higher surfactant concentrations than for the other surfactants considered in this study is a significant observation that can be easily rationalized from the simple principles of surfactant self-assembly outlined above. The higher concentrations of surfactant required for the quenching suggests a delay in the condensation of DNA induced by Ala, which can be attributed to the fact that the micellization of this surfactant occurs at a higher concentration. The quenching efficiency in these experiments can be related to the degree of condensation of the DNA, the most common interpretation, or the accessibility of the DNA inside the complex to the EB. The surfactant packing parameter, that is dependent on the relative sizes of the surfactant's polar and nonpolar parts, determines the type of aggregate that the surfactant will form, as outlined above. $^{29}$ Therefore, surfactants with bulkier head groups such as Pro and Phe, will form small spherical aggregates while larger aggregates are obtained with smaller head groups. With smaller micelles the DNA surface will be less covered (patch-like coverage) which allows for a residual binding of small molecules like EB. This is in good agreement with the fact that Ala quenches the EB more efficiently than Pro and Phe. This is also in good agreement with the gel electrophoresis experiments; the complexes formed with Phe, the surfactant that quenches EB less efficiently, are still visible in the wells after the charge neutralization.

In noting also that a simple surfactant with a small head group, like cetyltrimethylammonium bromide (CTAB), gives a more complete elimination of EB fluorescence than the surfactant studied here, we conclude that surfactants with small head groups displace EB efficiently, while with surfactants with large hydrophobic head groups, even if binding more strongly to DNA, as indicated by low CAC values, there is considerable 

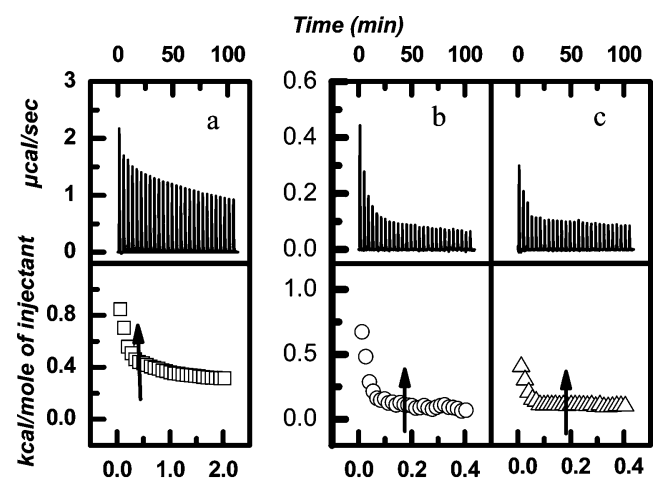

[Surfactant], mM

Figure 4. Isothermal titration calorimetry experiments corresponding to the additions of $250 \mu \mathrm{L}$ aliquots of surfactant solution ( $10 \mathrm{mM}$ for Ala and $2 \mathrm{mM}$ for Pro and Phe) into $1.425 \mathrm{~mL}$ of $10 \mathrm{mM}$ sodium phosphate buffer in 25 steps at the interval of $3 \mathrm{~min}$ at $25^{\circ} \mathrm{C}$ : upper panels show heat produced vs time and lower panels show enthalpy change per mole of surfactant vs the concentration of surfactant. (a) Ala; (b) Pro; and (c) Phe. Arrows indicate the CMCs obtained by surface tension measurements (Table 1).

residual EB binding to DNA. This is in agreement with simple self-assembly arguments, in that surfactants with large head groups only form small discrete micellar aggregates. Small aggregates, which repel each other, cannot fully cover the DNA double-helix and, therefore, not efficiently exclude the binding intercalators, like ethidium bromide. It is only with surfactants that form extended (effectively infinite) aggregates that full exclusion of an intercalator can be achieved. This is analogous to the situation of surfactant adsorption at solid surfaces: Surfactants that form spherical micelles show a much smaller coverage of the surface than that of rod micelles. (see, for example, ref 30).

Isothermal Calorimetry Titration Experiments. Isothermal titration calorimetry (ITC) allows the study of the heat of interaction between two cosolutes and has contributed significantly to the understanding of polymer-surfactant interactions and surfactant aggregation (see for example, refs $^{54-63}$ ). These experiments were conducted by step-bystep injections of a constant volume $(10 \mu \mathrm{L})$ of concentrated surfactant solution into a cell containing the buffer only or plasmid DNA solution (100 $\mu \mathrm{M}$ in phosphate groups). The thermograms of the titrations of the surfactant solutions into the buffer solution are shown in the upper panel of Figure 4. These thermograms contain a raw heat signal subtracted from the baseline and are denoted by cell feedback (CFB) in $\mu \mathrm{cal} /$ $s$. The injection of the concentrated surfactant solutions into the buffer produces a large endothermic heat signal more or less consistent throughout the experiments. The corresponding heat of enthalpy change per mole of surfactant, total area under each peak, normalized by the injectant concentration, is presented in the lower panel of Figure 4. The enthalpy change at the initial stage of addition of the surfactant stock solution (which is always higher than the CMC) to the buffer solution essentially stands for micellar dilution, demicellization, and dilution of the surfactant monomers. ${ }^{63,64}$ The enthalpy change at the final stage of addition of the surfactant solution is mainly associated with micellar dilution, as the final concentration of surfactant in the cell is now above the CMC.

The picture is very different when the surfactant titration is done into a solution of plasmid DNA. Instead of an endothermic enthalpy change, an exothermic enthalpy change

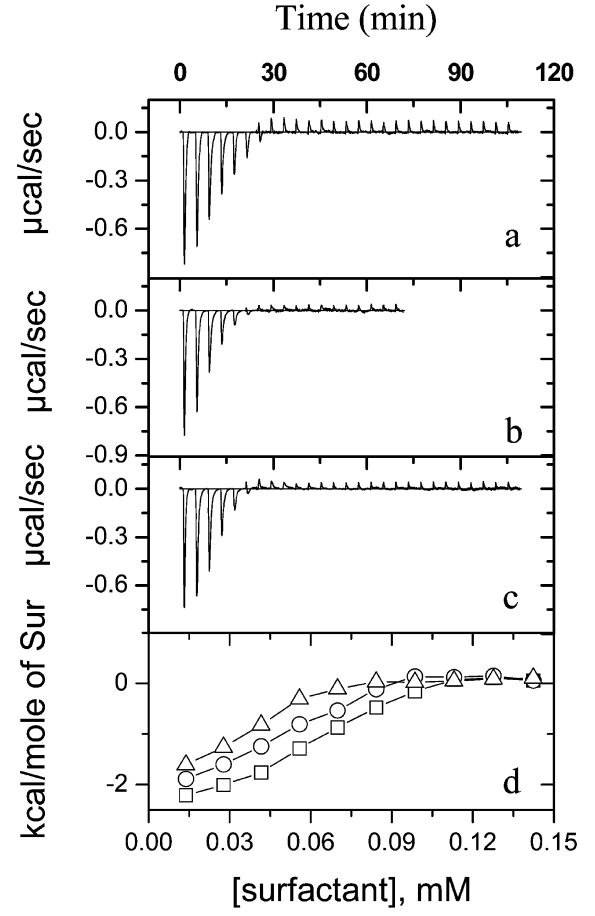

Figure 5. Results from isothermal titration calorimetry experiments. Sample raw data for the titration of (a) Ala, (b) Pro, and (c) Phe into plasmid DNA duplex solution at $25^{\circ} \mathrm{C}$ in $10 \mathrm{mM}$ sodium phosphate buffer. Each peak shows the heat produced by a serial injection of an aliquot of the concentrated surfactant solution into the DNA solution (100 $\mu \mathrm{M}$ in phosphate groups). (d) Enthalpy changes obtained from integration with respect to time, with appropriate molar correction (see the text) vs surfactant concentration for Ala $(\square)$, Pro $(\bigcirc)$, and Phe $(\Delta)$.

is now observed at the initial stages of the titration process (Figure 5). The enthalpy changes for the first few injections become exothermic and decrease steadily upon further injection of surfactant in all cases. The differential enthalpic curves, as shown in Figure 5d, contain observed enthalpy changes $(\Delta H)$ for each injection of the surfactant solutions into the DNA solutions plotted against the surfactant concentration. It can be observed that enthalpy changes were saturated when the surfactant concentration in the cell reached around 100,80 , and $60 \mu \mathrm{M}$ for Ala, Pro, and Phe, respectively. These concentrations correspond to $Z_{+/-}$values of 1.0, 0.8, and 0.6, which are in good agreement with the ethidium bromide exclusion assay and gel electrophoresis experiments. The observation establishes the fact that surfactants with more complex/bulkier hydrophobic head group, such as, phenylalanine and proline, show a stronger interaction with DNA (Phe $>$ Pro $>$ Ala) at a lower charge ratio. The overall enthalpy change in the presence of DNA includes the enthalpy changes for all the processes in the absence of the DNA, as explained above, along with the additional enthalpy changes due to interaction of the surfactant with DNA and all kinds of conformational changes of the DNA, including change in hydration upon interaction. The overall enthalpy change is the sum of the contributions from each of these processes and a separation into individual components is not straightforward. However, the major contributions to the overall enthalpy change come from the enthalpy changes for the demicellization and the interaction between the surfactant and the DNA. At the initial stage of addition of surfactant, the overall exothermic enthalpy change suggests that the enthalpy change for the interaction is exothermic in nature since that for demicellization is endothermic in nature. 


\section{Wavelength, $\mathrm{nm}$}

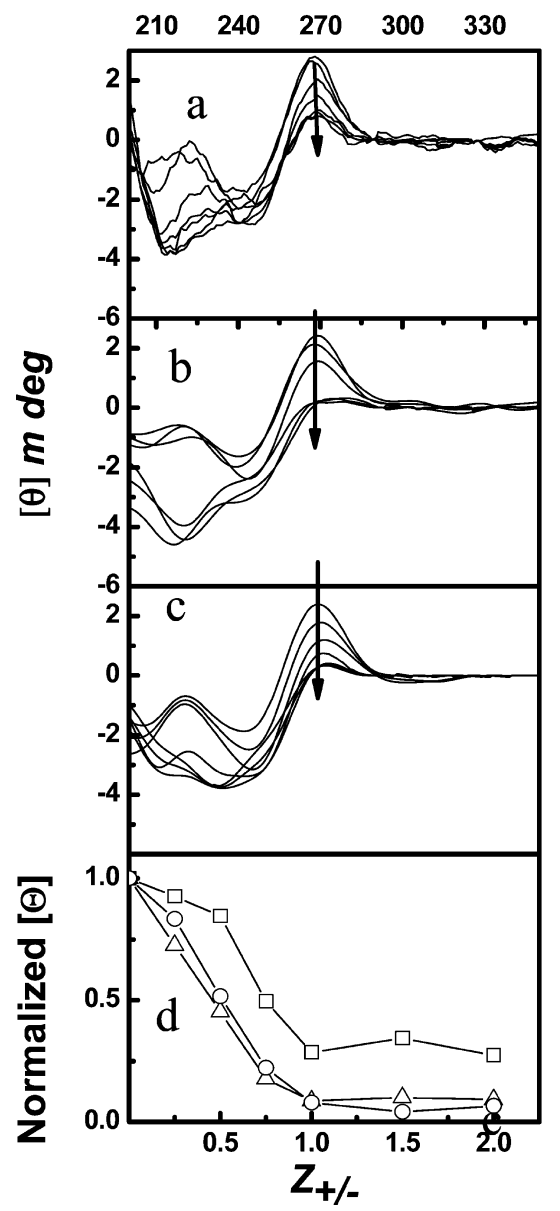

Figure 6. Circular dichroism spectrum of plasmid DNA $(100 \mu \mathrm{M}$ in phosphate groups) in the presence of varying amounts of (a) Ala, (b) Pro, and (c) Phe, with $Z_{+/-}=0,0.25,0.50,0.75,1.0,1.5$, and 2 (from top to bottom as marked by arrow headed line) in $10 \mathrm{mM}$ sodium phosphate buffer $\mathrm{pH} 7$ at $25^{\circ} \mathrm{C}$. The down-headed arrow indicates the increment of $Z_{+/-}$. (d) Normalized ellipticity at $274 \mathrm{~nm}\left([\Theta]_{\text {free }} \mathrm{DNA} /\right.$ $[\Theta]_{\text {complexed DNA }}$ ) as a function of $Z_{+/-}$for Ala $(\square)$, Pro $(\bigcirc)$, and Phe $(\Delta)$.

The average heats of interaction, obtained from the first two injections, are $-2.2,-1.8$, and $-1.6 \mathrm{kcal} / \mathrm{mol}$ of surfactant for Ala, Pro, and Phe, respectively. While a molecular interpretation of calorimetric data is never straightforward, the findings are consistent with a stronger interaction and a more complete coverage of DNA in the case of Ala than for the other two surfactants.

Circular Dichroism. The circular dichroism (CD) spectra of solutions of the three different surfactants and DNA were recorded for a series of molar ratios $\left(Z_{+/-}=0-2.0\right)$. The $\mathrm{CD}$ of plasmid DNA is significantly perturbed when complexed with these surfactants. Spectra at various charge ratios of surfactantto-DNA are illustrated in Figures $6 a-c$, whereas Figure $6 d$ shows the change in ellipticity of the DNA helix at $274 \mathrm{~nm}$ at various charge ratios for the three different surfactants to DNA. It can be noted that upon addition of each surfactant the characteristic features of the canonical B form, a positive band at $274 \mathrm{~nm}$, negative signal at $245 \mathrm{~nm}$, and crossover point near $258 \mathrm{~nm}^{65}$ are altered. The changes observed include an enhanced negative ellipticity, a flattening of the positive band, and a shift of both bands toward higher wavelength values. The spectra do not change significantly for charge ratios above 1.0 for Ala, 0.75 for Pro, and 0.6 for Phe complexes. The reduction in the

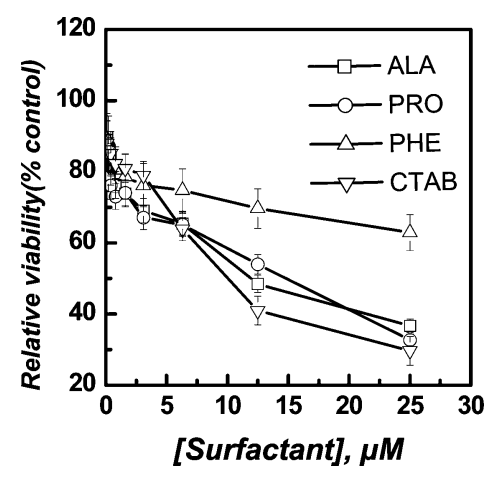

Figure 7. Effect of different surfactants on the viability of HeLa cells for Ala $(\square)$, Pro $(\bigcirc)$, Phe $(\Delta)$, and CTAB $(\nabla)$.

intensity of the $274 \mathrm{~nm}$ peak suggests a B-DNA to C-DNA transition; however, for this transition, the negative band should remain constant, which is not the case. The changes reported here have also been observed upon the interaction of DNA with cationic liposomes ${ }^{66-68}$ and polycations ${ }^{69}$ and have been attributed to "psi"-DNA condensation. ${ }^{70}$

The values obtained from at least three experiments indicate that the minimum intensity at $274 \mathrm{~nm}$ obtained on the addition of the three surfactants occurs on charge ratios of $1.0 \pm 0.1$, $0.75 \pm 0.1$, and $0.65 \pm 0.1$ for Ala, Pro, and Phe, respectively. The charge ratios defining the interactions between surfactant and DNA are in excellent agreement with those deduced from the gel electrophoresis and ethidium bromide exclusion experiments, as well as from the ITC studies, and support the notion of a more complete coverage of DNA in the case of Ala than for the other surfactants; in turn, this is referred to differences in self-assembly aggregates sizes as outlined above.

Cytotoxicity Studies. Even though surfactants belong to one of the most versatile and frequently applied excipients in pharmaceutical and cosmetic industries, cytotoxicity is a major barrier for in vitro and in vivo applications. Considering this, cytotoxicity studies of the surfactants were performed and results were compared with the values for cetyltrimethylammonium bromide (CTAB), a well-known cationic surfactant with the same chain length as the surfactants under study here. As observed from the results in Figure 7, the relative cell viability decreases with an increase in the concentration of surfactant. In the case of CTAB, the viability of HeLa cells decreased abruptly with increase in the concentration above $5 \mu \mathrm{M}$. Both Ala and Pro present a slightly higher toxicity than CTAB at lower surfactant concentrations but become less toxic than $\mathrm{CTAB}$ for concentrations higher than $5 \mu \mathrm{M}$. Phe was the surfactant that showed the lowest cytotoxicity, having a much slower decay with concentration and reaching a plateau of about $70 \%$ of cell viability. For example, at a surfactant concentration of $25 \mu \mathrm{M}$, only 29,40 , and $35 \%$ of cells survived in the presence of CTAB, Ala, and Pro, whereas cell survival was $70 \%$ in the presence of Phe.

It has been shown that the cytotoxicity of surfactants decreases on increasing the alkyl chain length, ${ }^{71}$ probably due to a lower activity. (For a surfactant, the activity equals the concentration below the CMC, while above the CMC it stays constant. Because the $\mathrm{CMC}$ decreases with the alkyl chain length, so will the activity. ${ }^{72,74}$ ) The low cytotoxicity of Phe, when compared with the other surfactants, is not in line with the relative CMC values that would give the surfactant unimer concentration and, thus, the activity; instead, we relate the behavior with the bulky head group or the larger hydrophobicity of the head group. In a previous study we have found that the 
cytotoxicity decreases substantially with increasing the number of hydroxyl substitutions (increasing the hydrophilicity) on the surfactant head group. ${ }^{11}$ It is thus possible that the presence of bulky groups on the surfactant head group plays an important role in shielding the amino groups, thus reducing their interaction with the cell surface. However, without a solid mechanistic understanding of toxicity such deductions, although of possible practical significance remain speculations.

It is interesting to note that the less cytotoxic surfactant, Phe, was also the one that started to interact with DNA at the lowest concentrations, as inferred from gel electrophoresis, EB exclusion experiments, and ITC measurements, as well as induced conformational changes in DNA at lower concentrations, as shown by $\mathrm{CD}$, but provided a less-efficient coverage of the DNA molecules, as the ethidium bromide exclusion experiments suggest. It is believed that the transfection of DNA into cells is limited by the absence of complex dissociation in the cytoplasm, or at least, by the fact that it is not accessible to the cell machinery. Also, it has been shown recently that the precompaction of DNA with amino acid-based cationic surfactants increases the transfection efficiency of commercially available liposome formulations. ${ }^{75}$ Based on this, we can speculate that, of the three surfactants under study, Phe is the most promising precompaction agent of DNA for gene transfection studies.

\section{Conclusions}

Here we describe a biophysical study of the interaction between DNA and amino acid-based surfactant molecules with varied architecture. It was observed that the formation of DNA - surfactant complexes is dependent on the hydrophobicity and/or the bulkiness of the surfactant head group. The more hydrophobic surfactant (Phe) interacted with DNA at lower mixing ratios, since the surfactant micelles were more readily formed at DNA (lower CAC). However, the accessibility of DNA to small molecules is preserved to a certain extent, that is, Phe excludes EB less efficiently. This observation is attributed to the formation of smaller and discrete surfactant aggregates for surfactants with larger head groups. In general, the DNA - surfactant aggregation can be rationalized from a general model of surfactant self-assembly taking into account the effective surfactant molecule shape, in turn determined by the bulkiness of the head group, as well as electrostatic and hydrophobic interactions. The fact that the more hydrophobic surfactant (Phe) also presents a lower cytotoxicity, even at relatively high surfactant concentrations, makes it a promising precompacting agent of DNA for gene delivery applications.

Acknowledgment. R.S.D, M.G.M., and B.L. acknowledge Fundação para a Ciência e a Tecnologia, Portugal (Grant SFRH/ BPD/24203/2005 and Projects POCTI/QUI/45344/2002 and POCTI/QUI/58689/2004). Authors acknowledge Swedish International Development Cooperation Agency (SIDA) for financial support.

\section{References and Notes}

(1) Dias, R. S., Lindman, B., Eds. In DNA Interactions with Polymers and Surfactants; John Wiley \& Sons: Hoboken, NJ, 2008; in press.

(2) Raspaud, E.; Toma, A. C.; Livolant, F.; Rädler, J. O. In DNA Interactions with Polymers and Surfactants; Dias, R., Lindman, B., Eds.; John Wiley \& Sons: Hoboken, NJ, 2008, pp 119-134.

(3) Örberg, M. L.; Schillen, K.; Nylander, T. Biomacromolecules 2007, 8, 1557-1563.

(4) Rosa, M.; Dias, R.; Miguel, M. D.; Lindman, B. Biomacromolecules 2005, 6, 2164-2171.
(5) Dias, R.; Mel'nikov, S.; Lindman, B.; Miguel, M. G. Langmuir 2000, 16, 9577-9583.

(6) Dias, R. S.; Lindman, B.; Miguel, M. G. J. Phys. Chem. B 2002, 106, 12608-12612.

(7) Cardenas, M.; Dreiss, C. A.; Nylander, T.; Chan, C. P.; Cosgrove, T.; Lindman, B. Langmuir 2005, 21, 3578-3583.

(8) Zhu, D. M.; Evans, R. K. Langmuir 2006, 22, 3735-3743.

(9) Hayakawa, K.; Santerre, J. P.; Kwak, J. C. T. Biophys. Chem. 1983, $17,175-181$.

(10) Izumrudov, V. A.; Zhiryakova, M. V.; Goulko, A. A. Langmuir 2002, 18, 10348-10356.

(11) Dasgupta, A.; Das, P. K.; Dias, R. S.; Miguel, M. G.; Lindman, B.; Jadhav, V. M.; Gnanamani, M.; Maiti, S. J. Phys. Chem. B 2007, 111, 8502-8508.

(12) Choi, H. S.; Kim, H. H.; Yang, J. M.; Shin, S. Biochim. Biophys. Acta 2006, 1760, 1604-1612.

(13) Fraley, A. W.; Pons, B.; Dalkara, D.; Nullans, G.; Behr, J. P.; Zuber, G. J. Am. Chem. Soc. 2006, 128, 10763-10771.

(14) Maier, M. A.; Esau, C. C.; Siwkowski, A. M.; Wancewicz, E. V.; Albertshofer, K.; Kinberger, G. A.; Kadaba, N. S.; Watanabe, T.; Manoharan, M.; Bennett, C. F.; Griffey, R. H.; Swayze, E. E. J. Med. Chem. 2006, 49, 2534-2542.

(15) Waterhouse, J. E.; Harbottle, R. P.; Keller, M.; Kostarelos, K.; Coutelle, C.; Jorgensen, M. R.; Miller, A. D. ChemBioChem 2005, 6, 12121223.

(16) Anwer, K.; Kao, G.; Rolland, A.; Driessen, W. H. P.; Sullivan, S. M. J. Drug Targeting 2004, 12, 215-221.

(17) Zhang, S. B.; Xu, Y. M.; Wang, B.; Qiao, W. H.; Liu, D. L.; Li, Z. S. J. Controlled Release 2004, 100, 165-180.

(18) Tecle, M.; Preuss, M.; Miller, A. D. Biochemistry 2003, 42, $10343-$ 10347.

(19) van Rossenberg, S. M. W.; van Keulen, A. C. I.; Drijfhout, J. W.; Vasto, S.; Koerten, H. K.; Spies, F.; van't Noordende, J. M.; van Berkel, T. H. C.; Biessen, E. A. L. Gene Ther. 2004, 11, 457-464.

(20) Trentin, D.; Hubbell, J.; Hall, H. J. Controlled Release 2005, 102, 263-275.

(21) Thierry, A. R.; Abes, S.; Resina, S.; Travo, A.; Richard, J. P.; Prevot, P.; Lebleu, B. Biochim. Biophys. Acta 2006, 1758, 364-374.

(22) Kodama, K.; Katayama, Y.; Shoji, Y.; Nakashima, H. Curr. Med. Chem. 2006, 13, 2155-2161.

(23) Le Ny, A. L. M.; Lee, C. T. J. Am. Chem. Soc. 2006, 128, 64006408.

(24) Blagbrough, I. S.; Geall, A. J.; Neal, A. P. Biochem. Soc. Trans. 2003, 31, 397-406.

(25) Ronsin, G.; Perrin, C.; Guedat, P.; Kremer, A.; Camilleri, P.; Kirby, A. J. Chem. Commun. 2001, 2234-2235.

(26) Bitton, R.; Schmidt, J.; Biesalski, M.; Tu, R.; Tirrell, M.; BiancoPeled, H. Langmuir 2005, 21, 11888-11895.

(27) Santoso, S. S.; Vauthey, S.; Zhang, S. G. Curr. Opin. Colloid Interface Sci. 2002, 7, 262-266.

(28) Israelachvili, J. Intermolecular and Surface Forces, 2nd ed.; Academic Press: London, 1991.

(29) Evans, D. F.; Wennerström, H. The Colloidal Domain. Where physics, chemistry and biology, and technology meet, 2nd ed.; Wiley-VCH: New York, 1999.

(30) Holmberg, K.; Jönsson, B.; Kronberg, B.; Lindman, B. Surfactants and Polymers in Aqueous Solution, 2nd ed.; John Wiley \& Sons, Ltd.: West Sussex, 2003.

(31) Lindman, B.; Thalberg, K. In Interaction of Surfactants with Polymers and Proteins; Goddard, E., Ananthapadmanabhan, K., Eds.; CRC Press: Boca Raton, FL, 1993; pp 203-276.

(32) Svensson, A.; Piculell, L.; Karlsson, L.; Cabane, B.; Jönsson, B. J. Phys. Chem. B 2003, 107, 8119-8130.

(33) Norrman, J.; Piculell, L. J. Phys. Chem B. 2007, 111, 13364-13370.

(34) Dias, R. S.; Miguel, M. G.; Lindman, B. In DNA Interactions with polymers and surfactants; Dias, R., Lindman, B., Eds.; John Wiley \& Sons: Hoboken, NJ, 2008, pp 89-118.

(35) Eskilsson, K.; Leal, C.; Lindman, B.; Miguel, M.; Nylander, T. Langmuir 2001, 17, 1666-1669.

(36) Costa, D.; dos Santos, S.; Antunes, F. E.; Miguel, M. G.; Lindman, B. Arkivoc 2006, 161-172.

(37) Roy, S.; Das, D.; Dasgupta, A.; Mitra, R. N.; Das, P. K. Langmuir 2005, 21, 10398-10404.

(38) Sambrook, J. E. F. Fritsch, E. J. T. Maniatis, T. Molecular Cloning: A laboratory manual; Cold Spring Harbor Laboratory Press: New York, 1989.

(39) Melnikov, S. M.; Sergeyev, V. G.; Yoshikawa, K. J. Am. Chem. Soc. 1995, 117, 9951-9956. 
(40) Lleres, D.; Clamme, J. P.; Dauty, E.; Blessing, T.; Krishnamoorthy, G.; Duportail, G.; Mely, Y. Langmuir 2002, 18, 10340-10347.

(41) Kudryashov, E.; Morrissey, S.; Gorelov, A.; Buckin, V.; Dawson, K. Biophys. J. 1997, 72, Wp362-Wp362.

(42) McLoughlin, D.; Imperor-Clerc, M.; Langevin, D. ChemPhysChem 2004, 5, 1619-1623.

(43) Zhou, S. Q.; Liang, D. H.; Burger, C.; Yeh, F. J.; Chu, B Biomacromolecules 2004, 5, 1256-1261.

(44) Ghirlando, R.; Wachtel, E. J.; Arad, T.; Minsky, A. Biochemistry 1992 31, 7110-7119.

(45) Dias, R. S.; Lindman, B.; Miguel, M. G. Prog. Colloid Polym. Sci. 2001, 118, 163-167.

(46) Ewert, K. K.; Evans, H. M.; Zidovska, A.; Bouxsein, N. F.; Ahmad, A.; Safinya, C. R. J. Am. Chem. Soc. 2006, 128, 3998-4006.

(47) Koltover, I.; Salditt, T.; Rädler, J. O.; Safinya, C. R. Science 1998 , $281,78-81$

(48) Hsu, W. L.; Chen, H. L.; Liou, W.; Lin, H. K.; Liu, W. L. Langmuir 2005, 21, 9426-9431.

(49) Dias, R. S.; Lindman, B.; Miguel, M. G. J. Phys. Chem. B 2002, 106, 12600-12607.

(50) Rosa, M.; Morán, M. C.; Miguel, M. G.; Lindman, B. Colloids Surf., A 2007, 301, 361-375.

(51) Bilalov, A.; Leal, C.; Lindman, B. J. Phys. Chem. B 2004, 108, 15408 15414.

(52) Goracci, L.; Germani, R.; Savelli, G.; Bassani, D. M. ChemBioChem 2005, 6, 197-203.

(53) Chatterjee, R.; Chattoraj, D. K. Biopolymers 1979, 18, 147-166.

(54) Bloor, D. M.; Li, Y.; Wynjones, E. Langmuir 1995, 11, 3778-3781.

(55) McClements, D. J. J. Agric. Food Chem. 2000, 48, 5604-5611.

(56) Dai, S.; Tam, K. C.; Jenkins, R. D. J. Phys. Chem. B 2001, 105, 10189 10196.

(57) Hait, S. K.; Majhi, P. R.; Blume, A.; Moulik, S. P. J. Phys. Chem. B 2003, 107, 3650-3658

(58) Lad, M. D.; Ledger, V. M.; Briggs, B.; Green, R. J.; Frazier, R. A. Langmuir 2003, 19, 5098-5103.
(59) Bai, G. Y.; Nichifor, M.; Lopes, A.; Bastos, M. J. Phys. Chem. B 2005, 109, 518-525.

(60) Lapitsky, Y.; Parikh, M.; Kaler, E. W. J. Phys. Chem. B 2007, 111, 8379-8387.

(61) Majhi, P. R.; Blume, A. Langmuir 2001, 17, 3844-3851.

(62) Thurn, T.; Couderc, S.; Sidhu, J.; Bloor, D. M.; Penfold, J.; Holzwarth, J. F.; Wyn-Jones, E. Langmuir 2002, 18, 9267-9275.

(63) Mazer, N. A.; Olofsson, G. J. Phys. Chem. 1982, 86, 4584-4593.

(64) Bach, J.; Blandamer, M. J.; Bijma, K.; Engberts, J.; Kooreman, P. A.; Kacperska, A.; Rao, K. C.; Subha, M. C. S. J. Chem. Soc., Faraday Trans. 1995, 91, 1229-1235.

(65) Ivanov, V. I.; Minchenk, L.; Schyolki, A.; Poletaye, A. Biopolymers 1973, 12, 89-110.

(66) Bombelli, C.; Borocci, S.; Diociaiuti, M.; Faggioli, F.; Galantini, L.; Luciani, P.; Mancini, G.; Sacco, M. G. Langmuir 2005, 21, 1027110274.

(67) Bombelli, C.; Faggioli, F.; Luciani, P.; Mancini, G.; Sacco, M. G. J. Med. Chem. 2007, 50, 6274-6278.

(68) Zuidam, N. J.; Barenholz, Y.; Minsky, A. FEBS Lett. 1999, 457, 419422.

(69) Cao, Z. Q.; Liu, W. G.; Liang, D. C.; Guo, G.; Zhang, J. Y. Adv. Funct. Mater. 2007, 17, 246-252.

(70) Keller, D.; Bustamante, C. J. Chem. Phys. 1986, 84, 2972-2980.

(71) Courrier, H. M.; Krafft, M. P.; Butz, N.; Porte, C.; Frossard, N.; RemyKristensen, A.; Mely, Y.; Pons, F.; Vandamme, T. F. Biomaterials 2003, 24, 689-696.

(72) Wennerstrom, H.; Lindman, B. Phys. Rep. 1979, 52, 1-86.

(73) Lindman, B.; Puyal, M. C.; Kamenka, N.; Rymden, R.; Stilbs, P. J. Phys. Chem. 1984, 88, 5048-5057.

(74) Stilbs, P.; Lindman, B. J. Phys. Chem. 1981, 85, 2587-2589.

(75) Rosa, M.; Pereira, N. P.; Simões, S.; Lima, M. C. P.; Lindman, B.; Miguel, M. Mol. Membr. Biol. 2007, 25, 23-34.

BM8000765 